\title{
Research on Different Pricing Strategy in Dual Channel under the Circumstance of Electronic Commerce
}

\author{
Liu Zhiqiang, Wu Fanfan and Ren Xiangyang* \\ School of Economics and Management, Hebei University of Engineering, Han Dan, \\ 056038, P.R. China \\ hdliuliu@sohu.com,819751297@qq.com,*boyrenxy@126.com

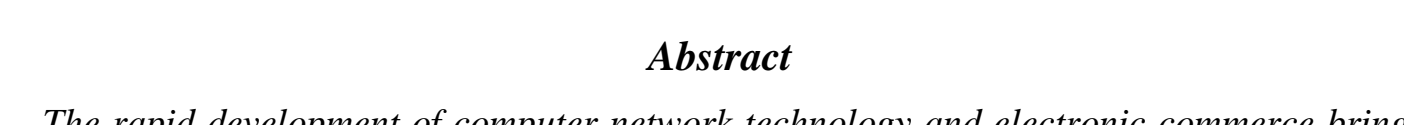 \\ The rapid development of computer network technology and electrohic commerce bring a \\ series of convenience to the people but also brings a lot of problems. At the same time, these \\ new computer technologies have forced many enterpuses to reconstrulct their distribution \\ channels by adding the electronic channel. In the real life, the conflict between the network \\ channel and traditional channel is an important problem. Supply chain has formed a network \\ in real life and cyber work. In this paper, we consider the problem of optimal decision of \\ supply chain and discuss the pricing strategy of manufacturers in the Stackelberg leader \\ follower strategy and the Bertrand strategy respective 1 . Finally, we analyze the equilibrium \\ price and profit of two strategies. The result show that a fixed pricing strategy for retailers \\ and manufacturers is not always advantageous with the changing of product price of \\ manufacturer. The first part is the research status and related problems. The second part is \\ the establishment of the model and the anatysis of and pricing strategy. The last part is the \\ experimental analysis and conclusion.
}

Keywords: Dual channel, Pricing Strategy, Game theory, E-commerce

\section{Introduction}

In the age of e-commerce, electronic channels have become an important retail channels for electronic channets 11. Computer electronic channels have formed a computer network and the computer fechnology has a deep impact on electronic channel. In recent years, the combinations of the electronic channel and traditional channel: dual channel become the main retail brands. Eyen some manufacturers shut down the network shop in order to reduce the conflict with the traditional retailers [2]. Electronic market becomes a new distribution channel with the development of computer network technology. The application of computer network technology is more and more wide used in the field of electronic commerce. At the same time, business circles and scholars pay a lot of attention to multi- channel environment of channel structure and channel conflict [3].

Manufacturers and distributors pursue the maximal interests as the goal of dual channels in the Double Marginalization Problem of classical [4]. Multi-channel problem under the computer electronic commerce environment gradually attracted researchers' attention. Friberg established a theoretical model of the relationship between the price of the traditional shops and the network electronic shop [5]. Based on the above literature, Friberg tested the Ecommerce data about books and CDs in network shop and pointed out that the price of the pure online store (only through the sale channel of network shop) is lower than the double channel store (also through the sale channel of network shop and traditional way ) [6]. Pan et 
al. established a price competition game model between a pure e-commerce retailer, an ecommerce and traditional business with retailers in the framework of Hotelling model and pointed out that the price of pure e-commerce retailer is usually lower than the retailer combine the e-commerce and traditional business [7]. Balasubramanian established the price competition of direct sales model (electronic commerce channels) and the traditional channels and studied market coverage on the equilibrium of electronic channels [8]. Chiang, Chajed and Hess researched the pricing problem of electronic channels points out that the electronic channel prices generally lower than the traditional channel prices [9]. Seong establish linear replacement demand function and analyze the profits of hybrid channels, traditional single channel, directly profit of three cases [10].

Researching on the problem of pricing simply can't solve the more and more serious channel conflict between the traditional channeland the network electronic chapnel brings. Many literatures focus on the coordination and incentive problems between manufacturers and distributors in traditional distribution channels and the study of mixed channels has only recently attracted attention. Demrongsir and Fan studied the effects of distribution costs and the service on dual channel and the result showed that the network electronic channel exists to increase supply chain profits [11]. Arya, Mittendorf and Sappingtou researched the Pareto improvement to realize the manufacturer and the retailers' profits under certain conditions when manufacturers produce the goods have a cost advantage and retailer distributed the product cost advantage on adding the direct onlihe channe1[12] Parlar Studied the horizontal product competition on substitutability problem [13]. Anupindi, et al. considered the coordination problems of horizontal competition on alternative products [14]. Tasy and Agrawal researched the coordination when the upstream is the suppliers and also is a competitor in downstream [15]. Yao and sLit believed manufacturer can solve the conflict between the electronic direct marketing channel and traditional channel by setting the appropriate wholesale price 10]. But Kurata argued that the wholesale price can't make the consistent effects on/dual channel supply chain but dynamic pricing strategy appropriate can make that and all parties can get benefit when the competition of brand and channel contention existing at the same time [17]. Yan exploited the electronic direct channel can help retailers to improve the serve level and suggests that in a certain range. This way can coordinate the double channel [18]. Cai and Zhang pointed out that the price discount contract can improve the dual Channel supply chain performance effectively through adjusting the traditional distribution channel prices and electronic direct channel price [19]. Yan and Huang researched the coordmation of two dual channel supply chains in the sensitive demand condition [20] $\mathrm{Qu}$ and Guo shared coordination contract of the dual channel supply chain through improving income [21]. Xie and Huang implemented the quantity discount model and make the two sides to achieve a win-win by adjusting the quantity discount rate in dual channel supply chain coordination [22]. Chiang designed a shared mechanism which shares the holding inventory cost and the direct channel gains. This mechanism makes the dual channel supply chain coordinate [23]. Liu and Zhang found that the income of the manufacturers increases as the retailer's profit always decreases. But retailers still insist on getting into a price discrimination strategy to prevent manufacturers electronic direct sales channel when manufacturers add online electronic channel in the information technology environment of direct sales channels and retailers implement price discrimination strategy to customer [24]. Gupta and Loulou studied sharing revenue of manufacturers and suppliers will increase the profits of manufacturers and suppliers under certain conditions when the input cost innovative manufacturers share its suppliers [25].

In this paper, we study the pricing strategy of a dual channel. This channel is consisted of a manufacturer and a retailer. Manufacturers and distributors maximize their own profits 
through pricing the price of the product they sell in electronic channel and the retail channel. There are two pricing strategies to choose (Stackelberg pricing strategy and Bertrand pricing strategy). Then we consider the pricing strategies and the profit of the manufacturer and distributor under different game models. We find that the pricing strategies for manufacturer and distributor are different under different situations. But there will be a coordination mechanism to for manufacturer and distributor to realize win-win in the circumstance of computer network.

\section{The Model and the Analysis of Pricing Strategy}

\subsection{The Assumption of the Model and Parameters}

This paper hypothesizes based on the actual situation: customers needn'tpay the fee, and the manufacturer has to pay for the cost. We assume that the manufacturer and distributor are rational and the information is symmetrical.

Description of variables and parameters

$p_{1}$ : the price of the product in traditional channe

$p_{2}$ the price of the product in electronic chanmel

$\omega$ : the price of the product manufacturen sells to retailer

$c_{1}$ : unit cost of sales in traditional channel and is paid by distributor

$c_{2}$ : unit cost of sales of manufacture

$c_{3}$ : unit cost of sales in electronic channel and is paid by manufacture

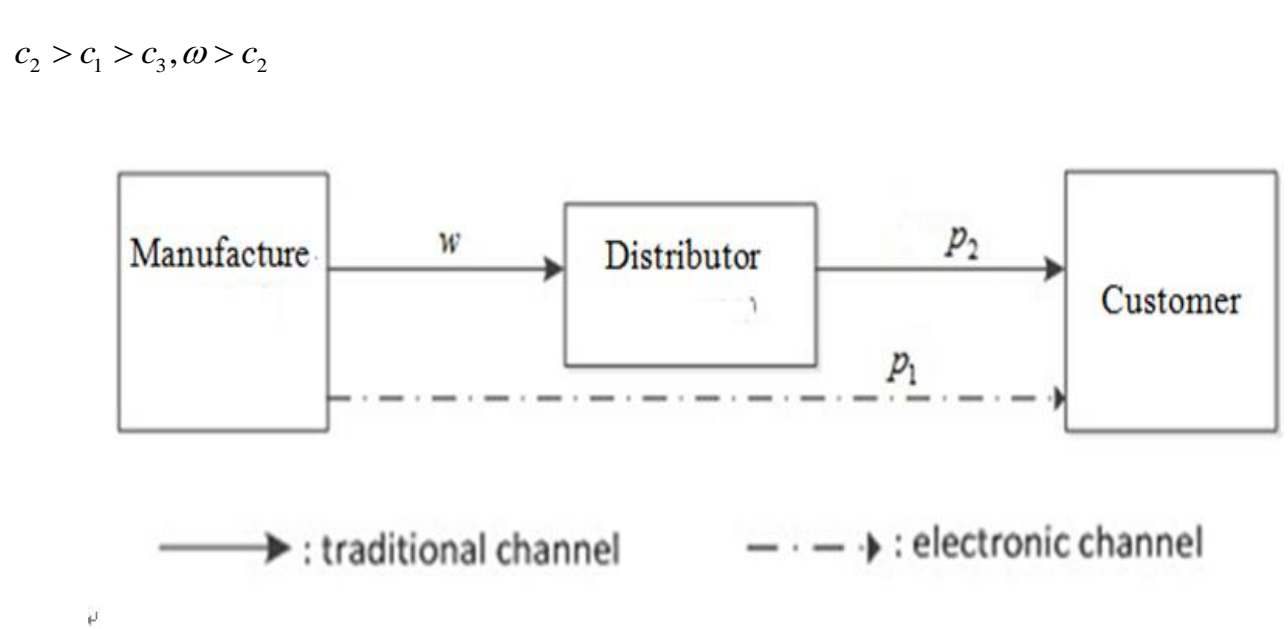

Figure 1. Schematic Diagram of Double Channel Model

$c_{2}>c_{1}$ means the cost of the production is greater than the cost of sales; we assume $c_{1}>c_{3}$ in order to reflect the characteristic of low cost in electronic sales channel. This means the unit cost of sales of the traditional distribution channels is greater than the unit cost of sales of the electronic distribution channels. This paper mainly discusses the pricing strategy and the conflict between the traditional channel and the electronic channel. We assume $\omega$ is an exogenous variable and determined by the market. This is 
in order to put the emphasis on pricing products of manufacturer and distributor, but also to facilitate the processing.

The demand function of distributor in traditional channel is:

$$
d_{1}=k_{0}-k_{1} p_{1}-k_{2}\left(p_{1}-p_{2}\right)
$$

The demand function of manufacture in electronic channel is:

$$
d_{2}=k_{2}\left(p_{1}-p_{2}\right), d_{1} \geq 0, d_{2} \geq 0, p_{1}>p_{2}>\omega
$$

If $p_{2}<\omega$, distributor can enlarge purchase from electronic channel and then sell in the traditional channel to get more profits. Obviously this is the original intention of the manufacturers to increase electronic distribution channels. $k_{0}, k_{1}, k_{2}$ is gonstant. $k_{0}$ means the primary need in the whole market. $k_{1} p_{1}$ means changes of distributors demand caused by a change in the price. $k_{2}\left(p_{1}-p_{2}\right)$ means change of denand of distributors caused by the price difference between the two channels. $\angle d_{1}$ can be indicated as $d_{1}=k_{0}-\left(k_{1}+k_{2}\right) p_{1}+k_{2} p_{2} . d_{1}$ is Linear demand fundion We use the liphear demand function for the following reasons: firstly the linear demand function can express the demand changes caused by the price difference between channels, secondly studies have shown that some commodity demand is linear or linear approximation. As the demand of some online sales products are linear. Last, linear demand function has been adopted by a lot of supply chain management literature because of its simplieity and easy processing.

When manufacture adds the electronic channel, the demand for electronic channel is caused by the price difference between two channels. But the product demand of the whole is metabolic. The whole demand of the product is $d_{1}+d_{2}=k_{0}-k_{1} p_{1}$. Actually there is a certain function relation between $p_{1}$ and $p_{2}$. The change of $p_{2}$ will bring the change of $p_{1}$ and then affect the whole market demand, namely $d_{1}+d_{2}=k_{0}-k_{1} p_{1}\left(p_{2}\right)$.

The profit function ob distributor is.

$$
\tau_{4}=\left(p_{1}-\omega-c_{1}\right)\left(k_{0}-k_{1} p_{1}-k_{2}\left(p_{1}-p_{2}\right)\right)
$$

The profit function of nanufacture is:

$$
\begin{aligned}
\pi_{2}= & \left(\omega-c_{2}\right)\left(k_{0}-k_{1} p_{1}-k_{2}\left(p_{1}-p_{2}\right)\right)+ \\
& \left(p_{2}-c_{2}-c_{3}\right) k_{2}\left(p_{1}-p_{2}\right)
\end{aligned}
$$

The wholeprofit function of supply chain is:

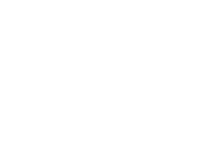

$$
\begin{aligned}
\Pi= & \pi_{1}+\pi_{2}=\left(p_{1}-c_{1}-c_{2}\right)\left(k_{0}-k_{1} p_{1}-k_{2}\left(-p_{2}\right)\right)+ \\
& \left(p_{2}-c_{2}-c_{3}\right) k_{2}\left(p_{1}-p_{2}\right)
\end{aligned}
$$

The decision variables of manufacture is $p_{2}$ and the decision variables of distributor is $p_{1}$.

\subsection{The Analysis of Pricing Strategy}

We assume manufacture adds the electronic channel and sets the price of electronic distribution channel. Distributor has two strategies to choose:

(1) Distributor sets his distribution price according to the price of the electronic channel. This is Stackelberg problem of manufacture being leader. 
(2) Distributor sets his distribution price without considering the price of the electronic channel (or he doesn't know the price when decided). This is Bertrand problem between distributor and manufacture.

2.2.1. Manufacture is a Stackelberg Leader: manufacture chooses $p_{2}$ to maximize the profit $\pi_{2}$, then distributor chooses $p_{1}$ according to $p_{2}$ as a follower to maximize the profit $\pi_{1}$. The solve order is in contrast to the sequence order in this game problem. The solving procedure is as follows:

The distributor calculates the optimal pricing strategy. Set $\partial \pi_{1} / \partial p_{1}=0$, the expression of $p_{1}$ on $p_{2}$ is:

$$
p_{1}^{M S}=\frac{k_{0}+k_{2} p_{2}^{M S}+\left(\omega+c_{1}\right)\left(k_{1}+k_{2}\right)}{2\left(k_{1}+k_{2}\right)}
$$

The manufacture can calculate the optimal pricing strategy' of distributon and elicit type (6), then choose $p_{2}$ to maximize the own profit. The profin function of manufacture can be express as $\pi_{2}\left(p_{2}\right)$ according to substitute type (6) into type (4).

Set $\partial \pi_{2}\left(p_{2}\right) / \partial p_{2}=0$

$$
p_{2}^{M S}=\frac{1}{2\left(k_{1}+k_{2}\right)}\left(k_{0}-2\left(Q+c_{1}\right)\left(k_{1}+k_{2}\right) c_{3}\left(k_{2}+2 k_{1}\right)+c_{2} k_{1}\right)
$$

We can get $p_{1}^{M S}$ with substituting type (6) into type (4).

So the optimal pricing strategies in Stackelberg model are:

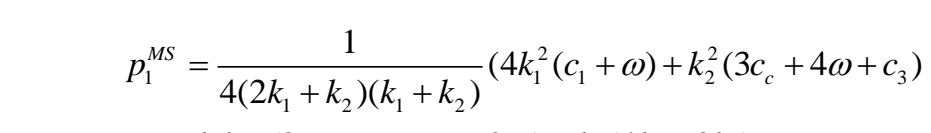

$$
\begin{aligned}
& \text { C }+k_{1} k_{2} \cdot\left(8 \omega+7 c_{1}+c_{2}+2 c_{3}\right)+k_{0}\left(4 k_{1}+3 k_{2}\right) \\
& p_{2}^{M S}-\frac{1}{2\left(2 k_{1}+k_{2}\right)}\left(k_{0}+\left(c_{1}+2 \omega\right)\left(k_{1}+k_{2}\right)+c_{3}\left(2 k_{1}+k_{2}\right)+\left(c_{2} k_{1}\right)\right.
\end{aligned}
$$

2.2.2. Bertrand Game between Manufacture and Distributor: Bertrand game is a kind of complete information static game. The main feature of this game is that both sides set the sale price at the same time. The game doesn't exist the sequence of action and manufacturer and distributor can make a decision meanwhile.

The best response strategy of the distributor is:

$$
p_{1}^{B}\left(p_{2}^{B}\right)=\frac{k_{0}+k_{2} p_{2}^{B}+\left(\omega+c_{1}\right)\left(k_{1}+k_{2}\right)}{2\left(k_{1}+k_{2}\right)}
$$

The best response strategy of the manufacture is:

$$
p_{2}^{B}=\frac{p_{1}^{B}+\omega+c_{3}}{2}
$$


We combine type (8) and type (9) to get the equilibrium price of this game:

$$
\begin{gathered}
p_{1}^{B}=\frac{2 k_{0}+\omega\left(2 k_{1}+3 k_{2}\right)+2 c_{1}\left(k_{1}+k_{2}\right)+k_{2} c_{3}}{4 k_{1}+3 k_{2}} \\
p_{2}^{B}=\frac{k_{0}+\left(3 \omega+c_{1}+2 c_{3}\right)\left(k_{1}+k_{2}\right)}{4 k_{1}+3 k_{2}}
\end{gathered}
$$

\subsection{The Comparative Analysis of Two Kinds of Game Equilibrium}

2.3.1. The Comparative Analysis of Equilibrium Price: we analyze the equilibrium price of two games:

$$
p_{1}^{M S}-p_{1}^{B}=\frac{k_{2}\left(k_{0} k_{2}+\left(c_{1}-2 c_{3}-4 \omega+3 c_{2}\right) k_{1} k_{2}+4\left(c_{2}-\omega\right) k_{1}^{2}+\left(c_{1}-c_{3}\right) k_{2}^{2}\right)}{4\left(2 k_{1}+k_{2}\right)\left(k_{1}+k_{2}\right)\left(4 k_{1}+3 k\right)}
$$

The first derivative of type (10) for $\omega$ is:

$$
\frac{d\left(p_{1}^{M S}-p_{1}^{B}\right)}{d \omega}=\frac{k_{1} k_{2}}{4\left(2 k_{1}+k_{2}\right)\left(4 k_{1}+3 k_{2}\right)}
$$

We know type (11) is less than zero for $\hat{k}_{1}>0, k_{2}>0$ So $p_{1}^{M S}-p_{1}^{B}$ decrease as $\omega$ increase.

Only when

$$
\omega_{1}=\frac{k_{0} k_{2}+\left(c_{1}-2 c_{3}+3 c_{2}\right) k_{1} k_{2}+4 c_{2} k_{1}^{2}+\left(c_{1}-c_{3}\right) k_{2}^{2}}{4\left(k_{1}^{A}+k_{2}\right) k_{1}}
$$

To sum up, the refationship between equilibrium prices of the distributor is:

$$
\begin{cases}p_{1}^{M S}<p_{1}^{B}, \text { when } & \omega>\omega_{1} \\ p_{1}^{M S}=p_{1}^{B}, \text { when } & \omega=\omega_{1} \\ p_{1}^{M S}>p_{1}^{B}, \text { when } & \omega<\omega_{1}\end{cases}
$$

The only critical point is

$$
\omega_{2}=\frac{k_{0} k_{2}+\left(c_{1}-2 c_{3}+3 c_{2}\right) k_{1} k_{2}+4 c_{2} k_{1}^{2}+\left(c_{1}-c_{3}\right) k_{2}^{2}}{4\left(k_{1}+k_{2}\right) k_{1}}
$$

And the relationship between $p_{2}^{M S}, p_{2}^{B}$ is:

$$
\begin{cases}p_{2}^{M S}<p_{2}^{B}, \text { when } & \omega>\omega_{2} \\ p_{2}^{M S}=p_{2}^{B}, \text { when } & \omega=\omega_{2} \\ p_{2}^{M S}>p_{2}^{B}, \text { when } & \omega<\omega_{2}\end{cases}
$$

Compare type (12) and type (13), we find $\omega_{1}=\omega_{2}$.And we get conclusion: 
Conclusion 1: the relationship of the equilibrium price of the manufacturer and distributor in different wholesale price range under two different pricing strategies is:

$$
\left\{\begin{array}{c}
p_{1}^{M S}<p_{1}^{B}, p_{2}^{M S}<p_{2}^{B}, \text { when } \quad \omega>\omega_{0} \\
p_{1}^{M S}=p_{1}^{B}, p_{2}^{M S}=p_{2}^{B}, \text { when } \quad \omega=\omega_{0} \\
p_{2}^{M S}>p_{2}^{B}, p_{2}^{M S}>p_{2}^{B}, \text { when } \quad \omega<\omega_{0} \\
\omega_{0}=\omega_{1}=\omega_{2}
\end{array}\right.
$$

2.3.2. A Comparative Analysis of the Equilibrium Profit: The price difference of distributor in these two pricing strategies can be expressed as:

$$
\begin{gathered}
\pi_{1}^{M S}-\pi_{1}^{B}=A_{1} \omega^{2}+B_{1} \omega+C_{1} \\
A_{1}=\frac{k_{1}^{2} k_{2}\left(k_{1} k_{2}\right) 8\left(k_{1}+5 k_{2}\right)}{\left(2 k_{1}+k_{2}\right)^{2}\left(4 k\left(+3 k_{2}\right)^{2}\right.}>0 \\
B_{1}^{2}-4 A_{1} C_{1}>0
\end{gathered}
$$

If $\pi_{1}^{M S}-\pi_{1}^{B}$,we can get the two unequalreal roots $\omega_{3}, \omega_{4}$ and $\omega_{3}=\omega_{0}$.

Set

The relationship between $\omega_{4}$ and $\omega_{0}$ is:
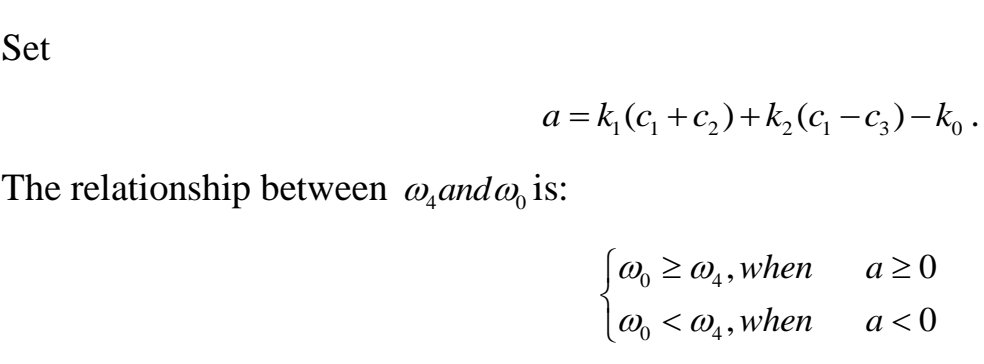

We set $\omega^{\prime}=\max \left\{c_{2}, \omega_{4}\right\}$

If $a \geq 0$

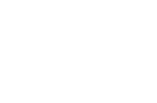

$$
\begin{gathered}
\begin{cases}\pi_{1}^{M S}>\pi_{1}^{B}, \text { when } & \omega>\omega_{0} \\
\pi_{1}^{M S}=\pi_{1}^{B}, \text { when } & \omega=\omega_{0} \\
\pi_{1}^{M S}<\pi_{1}^{B} \text {, when } \quad \omega^{\prime}<\omega<\omega_{0}\end{cases} \\
\begin{cases}\pi_{1}^{M S}>\pi_{1}^{B}, \text { when } \quad \omega>\omega_{4} \quad \text { or } \quad c_{2}<\omega<\omega_{0} \\
\pi_{1}^{M S}=\pi_{1}^{B}, \text { when } \quad \omega=\omega_{0} \quad \text { or } \quad \omega=\omega_{4} \\
\pi_{1}^{M S}<\pi_{1}^{B}, \text { when } \quad \omega_{0}<\omega<\omega_{4}\end{cases}
\end{gathered}
$$$$
\text { If } q<0
$$

The price difference of distributor in these two pricing strategies can be expressed as:

$$
\pi_{2}^{M S}-\pi_{2}^{B}=8 \frac{k_{2}\left(k_{1} k_{2}+\left(c_{1}-2 c_{3}-4 \omega-3 c_{2}\right) k_{1} k_{2}+4\left(c_{2}-\omega\right) k_{1}^{2}+\left(c_{1}-c_{3}\right) k_{2}^{2}+k_{0} k^{2}\right)^{2}}{4\left(4 k_{1}+3 k_{2}\right)^{2}\left(2 k_{1}+k_{2}\right)\left(k_{1}+k_{2}\right)} \geq 0
$$

Only when $\omega=\omega_{0}, \pi_{2}^{M S}=\pi_{2}^{B}$. 
Namely:

$$
\begin{cases}\pi_{2}^{M S}>\pi_{2}^{B}, \text { when } & \omega \neq \omega_{0} \\ \pi_{2}^{M S}=\pi_{2}^{B}, \text { when } & \omega=\omega_{0}\end{cases}
$$

\subsubsection{Analysis of Pricing Strategies:}

1) When $\omega=\omega_{0}, \pi_{2}^{M S}=\pi_{2}^{B}$. The profits of manufacture is the same in two pricing strategies. The profits of the distributor is the same in two pricing strategies too because of $\pi_{1}^{M S}=\pi_{1}^{B}$. So there is no motivation for manufacture and distributor change the current pricing strategy. The best strategy for the manufacture and distributor is keeping the current strategy.

2) When $1<0, \omega>\omega_{4}$ or $c_{2}<\omega<\omega_{0} ; a \geq 0, \omega>\omega_{0}$, distributor will chloose the pricing strategy of manufacture being a Stackelberg leader as $\pi_{1}^{\text {M }}>\pi_{1}$; manufacture will choose the pricing strategy of manufacture being a Stackelberg leader as $\pi_{2}^{M S}>\pi^{B}$. So manufacturer and distributor all will choose the pricing strategy of manufacture being a Stackelberg leader.

There is no conflict between the manufacturer and distributor of the choice about pricing strategy and under the above two kinds of circurnstances.

3) When $a<0, \omega_{0}<\omega<\omega_{4} ; a \geq 0, \omega^{\prime}<\omega<\omega_{0}$, distribator will choose the pricing strategy of Bertrand as $\pi_{1}^{M S}<\pi_{1}^{B}$; manufacture will choose the pricing strategy of manufacture being a Stackelberg leader as $\pi_{2}^{M S}>\pi_{2}^{B}$ So there is a conflict about the pricing strategy between manufacturer and distributor. The optimal choice of any side will damage the profit of another side. We need the Coordinate incentive mechanism to solve the conflict of profit between manufacturers and distributors.

In order to analyze problems we put forward Pareto strategy of this problem and it is defined as follows:

Definition 1: If the profilo the manufacturer and distributor under the strategy $A$ is no less than that under the strategy $A_{0}$ and the profit of at least one of manufacturer and distributor under the strategy $A$ is higher than that under the strategy $A_{0}$, we call the strategy $A$ is Paretofefective.

We set:

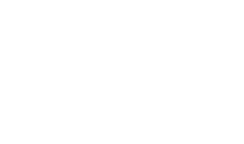

$$
\begin{aligned}
\Delta= & \left(\pi_{2}^{M S}-\pi_{2}^{B}\right)-\left(\pi_{1}^{M S}-\pi_{1}^{B}\right) \\
& =\left(\pi_{2}^{M S}+\pi_{1}^{M S}\right)-\left(\pi_{2}^{B}+\pi_{1}^{B}\right)=\Pi_{M S}-\Pi_{B}
\end{aligned}
$$

After calculation and simplify the processing can be expressed as

$$
\begin{gathered}
\Delta=A_{2} \omega^{2}+B_{2} \omega+c_{2} \\
A_{2}=\frac{2 k_{1}^{2} k_{2}\left(k_{1}+k_{2}\right)\left(12 k_{1}+7 k_{2}\right)}{\left(2 k_{1}+k_{2}\right)^{2}\left(4 k_{1}+3 k_{2}\right)^{2}}>0 \\
B_{2}^{2}-4 A_{2} C_{2}>0
\end{gathered}
$$

If $\Delta=0$, there are two different real roots of this function $\omega_{5}, \omega_{6}$, and $\omega_{5} \geq \omega_{4}$. 
When $a \geq 0$, there is $\omega_{0} \geq \omega_{5} \geq \omega_{4}$; When $a<0$, there is $\omega_{0} \leq \omega_{5} \leq \omega_{4}$.

We set $\omega^{\prime \prime}=\max \left\{c_{2}, \omega_{5}\right\}$ and we divided into two situations to discuss the total profit of the pricing strategy.

(1) When $a \geq 0, \omega^{\prime \prime}<\omega<\omega_{0}, \Delta=\Pi_{M S}-\Pi_{B}<0$; when $a<0, \omega_{0}<\omega<\omega_{5}, \Delta=\Pi_{M S}-\Pi_{B}<0$, namely $\pi_{2}^{M S}-\pi_{2}^{B}<\pi_{1}^{B}-\pi_{1}^{M S}$. When a manufacturer and distributor choose Bertrand pricing strategy, the distributor's profit increased value is greater than the profits of the manufacturers to reduce the value with respect to the Stackelberg pricing strategy of manufacturer being leader.,

$T_{B}$ is transfer payment that distributor delivery to the manufacturer when the manuacturer and distributor choose Bertrand pricing strategy. When supply chain implements transfer payment, the profit of manufacturer is $T_{B}+\pi_{2}^{B}$, the profit of the distributor is $\pi_{1}^{B}-T_{B} \cdot T_{B}$ should meet $T_{B}+\pi_{2}^{B}>\pi_{2}^{B}$ and $\pi_{1}^{B}-T_{B}>\pi_{1}^{B}$, namely $\pi_{1}^{B}-\pi^{M S}>T_{B}>\pi_{2}^{M S}-\pi_{2}^{B}$ to make Bertrand pricing strategy Pareto effective.

There is a constraint condition $\pi_{2}^{M S}-\pi_{2}^{B}<\pi_{1}^{B}-\pi_{1}^{M S}$ in 1), so $\Gamma_{B}$ exists. This means the coordination mechanism of the transfer payment is exists. Distributor can choose some kind of transfer payment to attract manufacturers to select Bettrapd strategy and make Bertrand strategy Pareto effective.

(2) When $a<0, \omega_{5}<\omega<\omega_{4}, A=\Pi_{M S}-\Pi_{B}>0$ namely $\pi_{2}^{M S}-\pi_{2}^{B}>\pi_{1}^{B}-\pi_{1}^{M S}$.This means manufacturer and distributor ehoose Stackelberg pricing strategy. Profit increased value of manufacturers is greater than the profits reduce value of distributor relative to Bertrand pricing strategy.

$T_{M S}$ is the transfer payment when a manufacturer and distributor choose Stackelberg pricing strategy.

When supply chain implements transfer payment, the profit of the manufacturer is $\pi_{2}^{M S}-T_{M S}$, the profit of the distributor is $\pi_{1}^{B}+T_{M S} \cdot T_{B}$ should meet $\pi_{2}^{M S}-T_{M S}>\pi_{2}^{B}$ and $\pi_{1}^{M S}+T_{M S}>\pi_{1}^{B}$, namely $\pi_{2}^{M S}-\pi_{2}^{B}>T_{M S}>\pi_{1}^{B}-\pi_{1}^{M S}$ to make Stackelberg pricing strategy Pareto effective.

There is a donstraint condition $\pi_{2}^{M S}-\pi_{2}^{B}>\pi_{1}^{B}-\pi_{1}^{M S}$ in 2), so $T_{M S}$ exists. This means the coordination mechanism of the transfer payment is exists.

We can get conclusion 2 from above information.

Conelusion 2: if manufacturer and distributor all have two pricing strategies to choose ( Stackelberg pricing strategy and Bertrand pricing strategy ), their choice are:

(1) When $\omega_{0}=\omega$, there is no motivation for the manufacturer and distributor to change the current pricing strategy. The best strategy is keeping the current strategy.

(2) When $a<0, \omega_{4}<\omega$ or $c^{2}<\omega<\omega_{4} ; a \geq 0, \omega>\omega_{0}$, manufacturer and distributor all will choose Stackelberg pricing strategy.

(3) When $a<0, \omega_{0}<\omega<\omega_{5} ; a \geq 0, \omega^{\prime \prime}<\omega<\omega_{0}$, there is a conflict between the manufacturer and distributor. Distributor can attract manufacturer to choose Bertrand pricing strategy by means of the transfer payment and make the Bertrand pricing 
strategy is Pareto effective. When $a<0, \omega_{5}<\omega<\omega_{4}$, there is a conflict between the manufacturer and distributor. Manufacturer can attract manufacturer to choose Stackelberg pricing strategy by means of the transfer payment and make the Stackelberg pricing strategy is Pareto effective.

\section{A Numerical Example}

We assume that $a=-20, k_{0}=50, k_{1}=4, k_{2}=2, c_{1}=3, c_{2}=20, c_{3}=15$.Then we obtain the relationship between the wholesale price and the profit of the manufacturer and distributor under different pricing strategies.

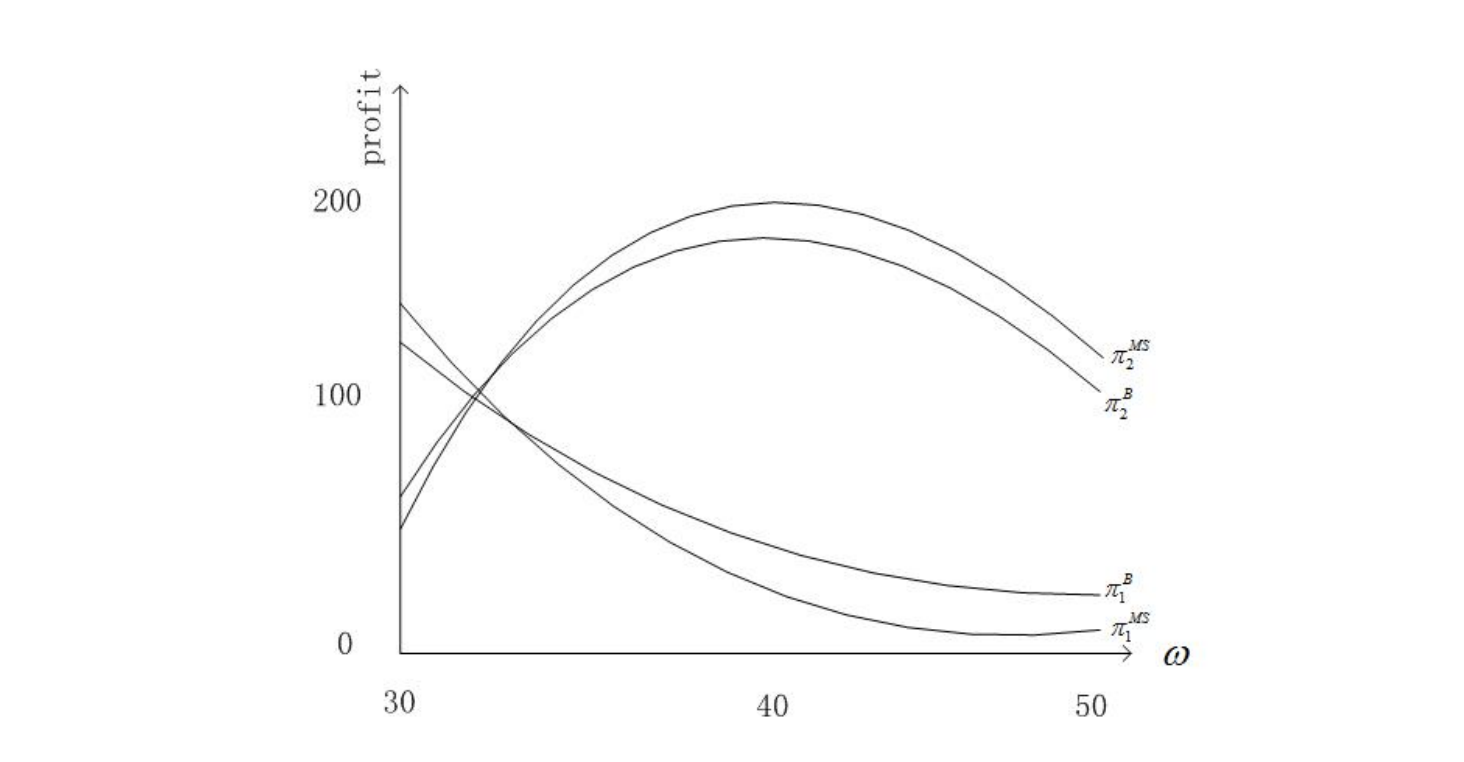

Figure 2. Manufacturer and Distributor under Different Pricing Strategies when

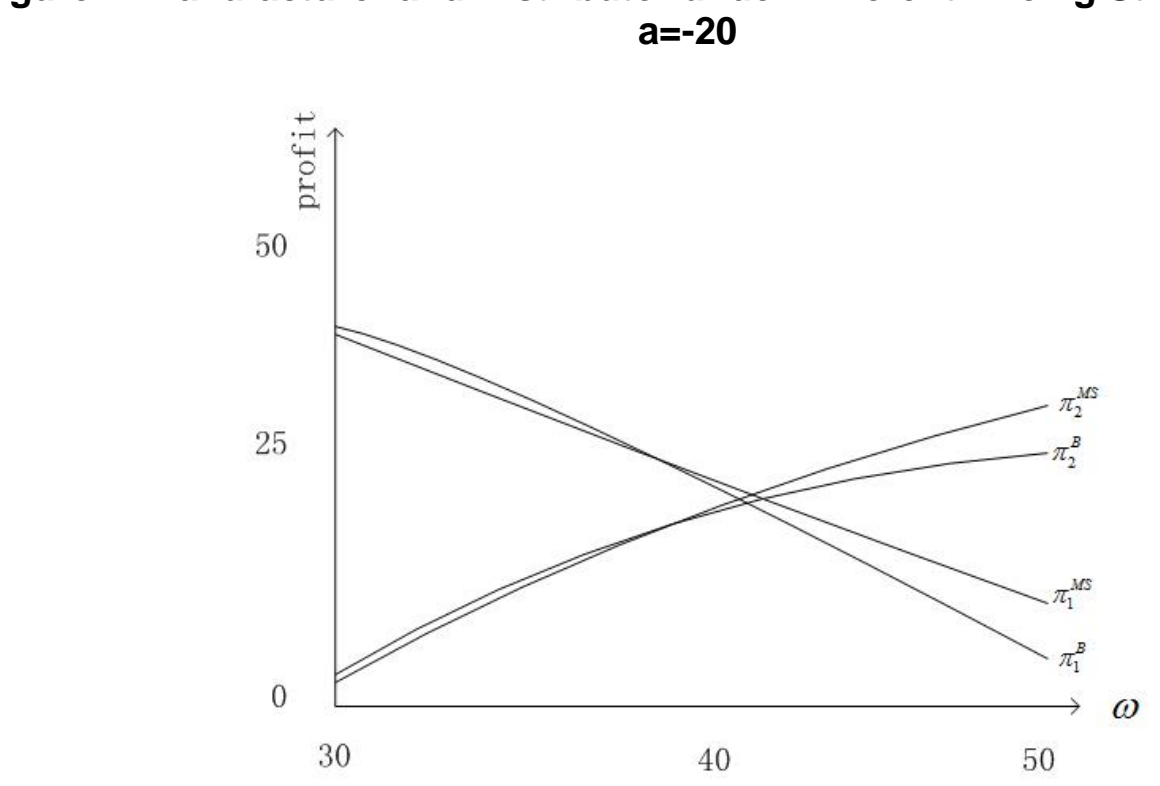

Figure 3. Manufacturer and Distributor under Different Pricing Strategies when $a=5$ 
We can see that when $a=-20, \omega=32.5$ and $a=5, \omega=39.8$, the profits of the manufacturer and distributor under two pricing strategies are same. The profit of the manufacturer and distributor under Stackelberg pricing strategy is larger than that under Bertrand pricing strategy in some cases for example $a=-20, \omega<32.5$. But in some cases, manufacturer prefers Stackelberg pricing strategy and distributor prefer Bertrand pricing strategy for example $a=-20, \omega>32.5$.

If the manufacturer chooses the Stackelberg pricing strategy and delivery some profit to the distributor through some contract, the profits of the manufacturer and distributor are larger than that under the Bertrand pricing strategy. At this time, the Stackelberg pricing strategy is Pareto effective.

\section{Conclusion}

In the real life, computer network technology has been integrate into people's lives, change the way we live and bring us convenience. Electronic commerce is an important example. Today, computer technology is applied in daily trade and the sum of business transactions of electronic commerce increases in geometrically speed. Computer technology allows us buy goods without going outside, but cause the conflict with the traditional channel. This problem change trouble many enterprises.

This paper establishes hybrid channels distribution model based on the electronic market. We discuss the pricing strategy of the manufacturer and distributor under Stackelberg pricing strategy and Bertrand pricing strategy. We analyze the two pricing strategies, and then we compare equilibrium price and the profits of the manufacturer and distributor under two different strategies. The conclusion is: there is a conflict between channels in some cange of price, but there exists a coordination mechanism to make one pricing strategy Pareto effectyve. This mechanism can reduce the conflict between the electronic channel and the traditional channel in circumstance of electronic commerce at the age of computer network. The research of this paper is based on information s mmetry hypothesis; cost and profit function of the manufacturer and distributor is the common Rnowledge. So the profit strategy of the manufacturer and distributor can be studie in future research when the information is asymmetric.

\section{References}

[1] M. Mangafindan, "Online retail sales are expected to rise to \$172 billion this year", The Wall Street Journal, (2006) May 24y

[2] S. Collett, "Channel conflicts push levis tonhalt web channel”, Computer World, vol. 33, no. 45, (1999), pp. 8-9.

[3] M. D. Smith, J. Bailey and E. Brynjolfsson, "Understanding Digital Markets: Review and Assessment", Wopking paper, USA: MITSloan School, (1999).

[4] J. J. Spengler, "Vertical restraints and antitrust policy", Journal of Political Economy, vol. 58, no. 5, (1950), pp. 347-352.

[5] R. Friberg, M. Ganslandt and M. Sandstrom, "E-commerce and prices-theory and evidence", Working paper series in economics and Finance No 389, Stockholm School of Economics, Sweden, (2000).

[6] R. Friberg, M. Ganslandt and M. Sandstrom, "Pricing strategies in e-commerce: Bricks vs. clicks. Working paper, Stockholm School of Economics, Sweden, (2001).

[7] X. Pan, V. Shankar and B. T. Ratchford, "Price competition between pureplay vs. bricks-and-clicks e-tailers: Analytical model and empirical analysis", Working paper, Smith School of Business, University of Maryland, (2002).

[8] S. Balasubramanian, "Mail versus mall: A strategic analysis of competition between direct marketers and conventional retailers", Marketing Science, vol. 17, no. 3, (1998), pp. 181 -195.

[9] W. K. Chiang, D. Chajed and J. D. Hess, "Directmarketing, indirectprofits: Astrategic analysis of dualchannel supply-chain design”, Management Science, vol. 49, no. 1, (2003), pp. 1-20. 
[10] Webb and L. Kevin, "Managing channels of distribution in the age of electronic commerce", Industrial Marketing Management, vol. 31, no. 3, (2002), pp. 95-102.

[11] A. Dumrongsiri, M. Fan, A. Jain and K. Moinzadeh, "A supply chain model with direct and retail channels", European Journal of Operational Research, vol. 187, no. 3, (2008), pp. 691-718.

[12] A. Arya, B. Mittendorf and D. E. M. Sappingtou, "The bright side of supplier encroachment", Marketing Science, vol. 26, no. 5, (2007), pp. 651-659.

[13] M. Parlar, "Game-theoretic analysis of the substitutable product inventory problem with random demands", Naval Research Logistics, vol. 35, no. 3, (1988), pp. 397-409.

[14] R. Anupindi, Y. Bassok and E. Zemel, "A general framework for the study of decentralized distribution systems", Manufacturing and Service Operations Management, vol. 3, no. 4, (2001), pp. 349-368.

[15] A. Tsay and N. Agrawal, "Channel Conflict and Coordination: An Investigation of Supply Chain Design", New Jersey: Santa Clara University, (1999).

[16] D. Q. Yao and J. J. Liu, "Competitive pricing of mixed retail and e -tail distribution channels", Omega, vol. 33, no. 3, (2005), pp. 235-247.

[17] H. Kurata, D. Q. Yao and J. J. Liu, "Pricing polices under direct vs indirect channel competition and national vs store brand competition", European Journal of Operational Research vol. 180, no. 1, (2007), pp. 262-281.

[18] R. Yan and Z. Pei, "Retail services and firm profit in a dual-channel market" Journal of Retailing and Consumer Services, vol. 16, no. 4, (2009), pp. $306-314$.

[19] G. Cai, Z. G. Zhang and M. Zhang, "Game theoretical perspectives on dual -channel supply chain competition with price discounts and pricing schemes", International Journal of Production Economics, vol. 117, no. 1, (2009), pp. $80-96$.

[20] N. Yan, X. Y. Huang and B. Liu, "Stackelberg Game Models of Supply Chain Dual-Channel Coordination in E-Markets", Chinese Journal of Management Science, vol. 15, no. 3,(2007), pp. 98-102.

[21] D. G. Qu and Y. J. Guo, "Coordination of Supply Chain with Hybrid Distribution Channels When Retailer's Demand Relies on Its Sales Effort”, Chinese Journal of Management Science, vol. 16, no. 3, (2008), pp. 8994.

[22] Q. H. Xie and P. Q. Huang, "A Quantity Discount Model for Coordination of Internet-based Hybrid Channels. Systems Engineering-Theory and Practice, vol. 27, no. 8, (2007), pp. 1-11.

[23] W. K. Chiang, "Product availability in competitiverand cooperative dual-channel distribution with stock out based substitution", European Journal of OperationalResearch, vol. 200, no. 1, (2010), pp. 111 -126.

[24] Y. Liu and J. J. Zhang, "The benefits of personalized pricing in a channel", Marketing Science, vol. 25, no. 1, (2006), pp. 97-105.

[25] S. Gupta and R. Loulou, "Process innovation product differentiation and channel structure: Strategic incentives in a duopoly, Making Science vol. 17, no. 4, (1998), pp. 301-316.
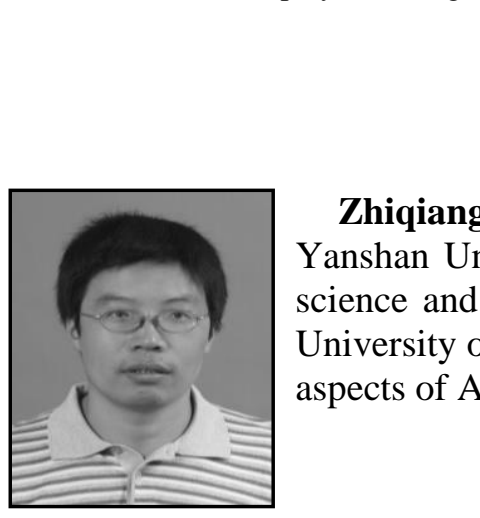

\section{Authors}

Zhiqiang Liu, He received his M. of Management (2003) from Yanshan University. Now he is full associate professor of management science and engineering at Economics Management Department, Hebei University of Engineering. His current research interests include different aspects of Artificial Intelligence and Logistics Engineering.

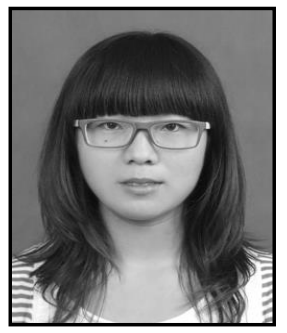

Fanfan Wu, She received her Bachelor's Degree of engineering management from university in 2012.Now she is a full-time student of Master Degree at Logistics Engineering Department in Hebei University of Engineering. Her current research interests include logistics and supply chain management. 


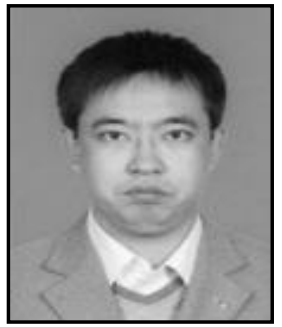

Xiangyang Ren, He received his M.Ms. in Management Science and Engineering (2006) from Hebei University of Engineering and $\mathrm{PhD}$ in Management Science and Engineering (2009) from China University of Mining and Technology (Beijing). Now he is associate professor of management at School of Economics and Management, Hebei University of Engineering. His current research interests include different aspects of Artificial Intelligence and Supply Chain Management.

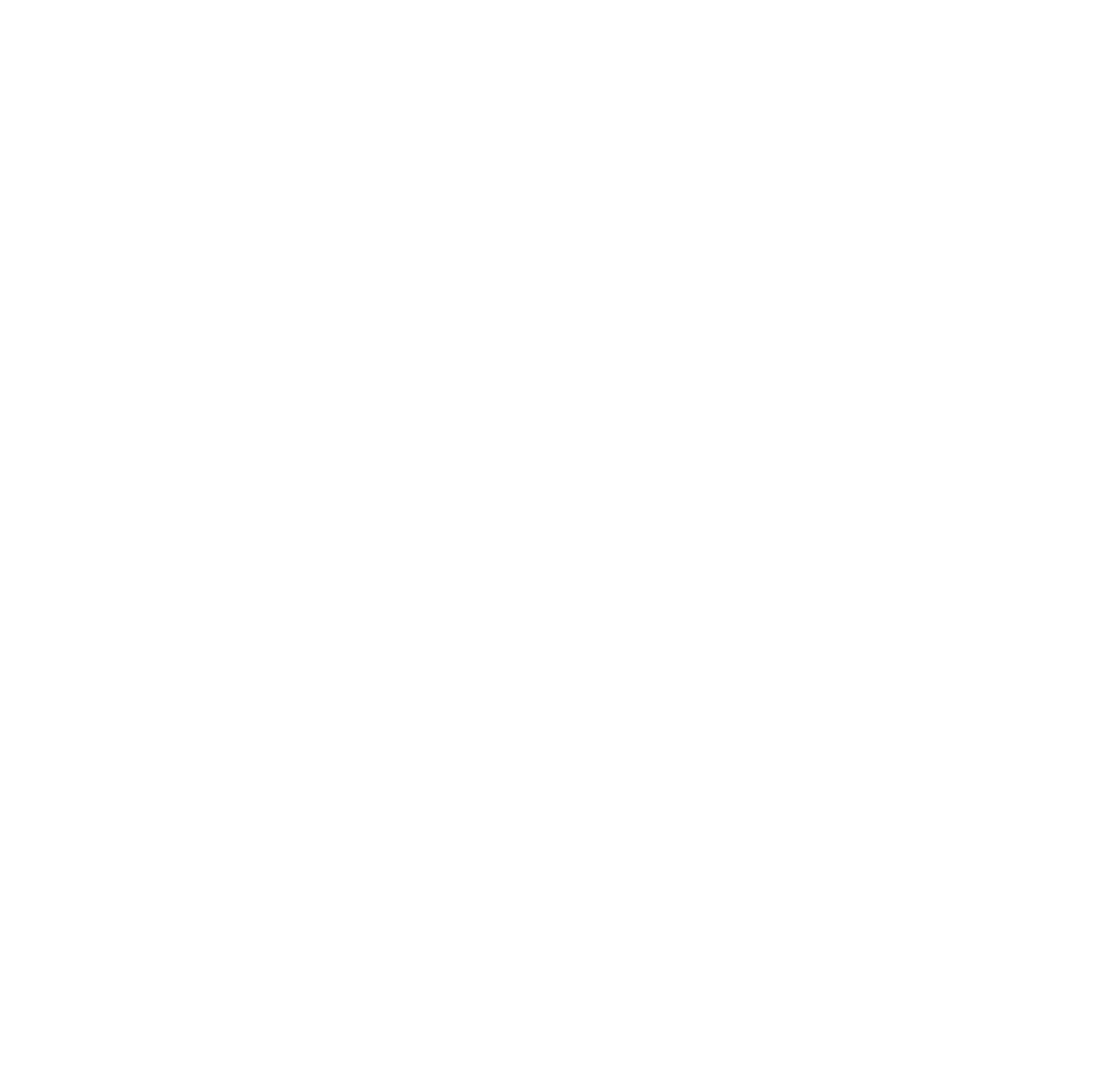


International Journal of Multimedia and Ubiquitous Engineering Vol.9, No.6 (2014)

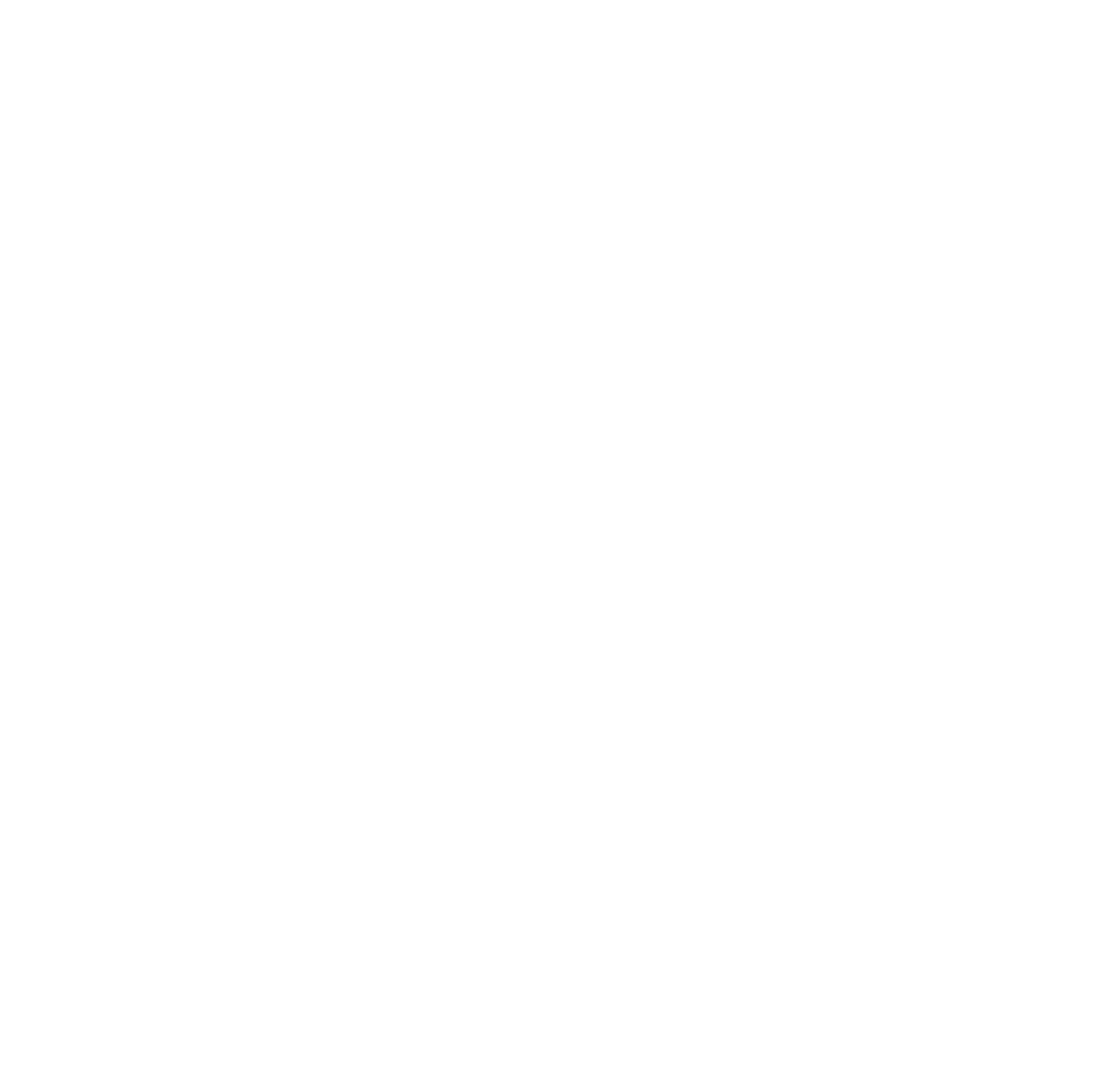

